\title{
mtDNAmanager: a Web-based tool for the management and quality analysis of mitochondrial DNA control-region sequences Hwan Young Lee ${ }^{1}$, Injee Song ${ }^{2}$, Eunho $\mathrm{Ha}^{3}$, Sung-Bae Cho ${ }^{2}$, Woo Ick Yang1 and Kyoung-Jin Shin*1
}

\author{
Address: ${ }^{1}$ Department of Forensic Medicine and Brain Korea 21 Project for Medical Science, Yonsei University College of Medicine, 250 \\ Seongsanno, Seodaemun-gu, Seoul 120-752, Korea, ${ }^{2}$ Department of Computer Science, Yonsei University, 262 Seongsanno, Seodaemun-gu, Seoul \\ 120-749, Korea and ${ }^{3}$ Department of Information and Statistics, Yonsei University, 234 Maeji-ri, Heungup-myun, Wounju-si, Gangwon-do 220- \\ 710, Korea \\ Email: Hwan Young Lee - hylee192@yuhs.ac; Injee Song - schunya@gmail.com; Eunho Ha - statha@yonsei.ac.kr; Sung- \\ Bae Cho - sbcho@cs.yonsei.ac.kr; Woo Ick Yang - wiyang9660@yuhs.ac; Kyoung-Jin Shin* - kjshin@yuhs.ac \\ * Corresponding author
}

Published: 17 November 2008

BMC Bioinformatics 2008, 9:483
Received: 18 September 2008

Accepted: 17 November 2008

This article is available from: http://www.biomedcentral.com//47/-2/05/9/483

(C) 2008 Lee et al; licensee BioMed Central Ltd.

This is an Open Access article distributed under the terms of the Creative Commons Attribution License (http://creativecommons.org/licenses/by/2.0), which permits unrestricted use, distribution, and reproduction in any medium, provided the original work is properly cited.

\begin{abstract}
Background: For the past few years, scientific controversy has surrounded the large number of errors in forensic and literature mitochondrial DNA (mtDNA) data. However, recent research has shown that using mtDNA phylogeny and referring to known mtDNA haplotypes can be useful for checking the quality of sequence data.

Results: We developed a Web-based bioinformatics resource "mtDNAmanager" that offers a convenient interface supporting the management and quality analysis of mtDNA sequence data. The mtDNAmanager performs computations on mtDNA control-region sequences to estimate the most-probable mtDNA haplogroups and retrieves similar sequences from a selected database. By the phased designation of the most-probable haplogroups (both expected and estimated haplogroups), mtDNAmanager enables users to systematically detect errors whilst allowing for confirmation of the presence of clear key diagnostic mutations and accompanying mutations. The query tools of mtDNAmanager also facilitate database screening with two options of "match" and "include the queried nucleotide polymorphism". In addition, mtDNAmanager provides Web interfaces for users to manage and analyse their own data in batch mode.
\end{abstract}

Conclusion: The mtDNAmanager will provide systematic routines for mtDNA sequence data management and analysis via easily accessible Web interfaces, and thus should be very useful for population, medical and forensic studies that employ mtDNA analysis. mtDNAmanager can be accessed at http://mtmanager.yonsei.ac.kr.

\section{Background}

The outstanding features of human mitochondrial DNA (mtDNA) - such as its high mutation rate, absence of recombination, stability and the large number of genome copies per cell - have led to its wide utilization in various disciplines, including population, medical and forensic genetics. For the past few years, scientific controversy has surrounded the large numbers of errors detected in much of the previously published mtDNA data $[1,2]$. In extreme cases erroneous data can alter the main conclusion of a 
study [3], requiring confirmation of the absence of errors before proceeding to further analysis or drawing meaningful conclusions. Since phylogenetic investigations and database screening could have detected prevalent errors in published data sets, methodologies based on mtDNA haplogroup determination and comparisons with existing mtDNA haplotypes were proposed for preventing mtDNA errors $[4,5]$. In particular, the phylogenetic approach which is the key tool used to understand the structure of the mtDNA data under study - was shown to be very useful for systematic reanalysis of an mtDNA data set. According to data and part of the phylogeny, it was reported to detect approximately $50 \%$ of all sequence errors [3] and hence has formed a starting point to localizing a sequence to a part of the phylogeny, at least to the level of the haplogroup for systematic error detection. Refinement of mtDNA phylogeny with more diagnostic mutations would facilitate the detection of more errors in mtDNA sequence data since it is based on mutation motifs, and if haplogroup determination fails, a neighbourhood search for sequences in the available database could identify a subset of potentially closely related sequences, thereby allowing researchers to pinpoint errors in the sequence by comparing the sequence in question with a limited subset of the total database [4]. However, manual haplogroup estimation requires a thorough understanding of the worldwide mtDNA phylogeny, and database screening for systematic error detection requires high-quality databases that are publicly available.

The Human Mitochondrial DataBase (HmtDB) has been designed and implemented using automatically running bioinformatics tools to facilitate mtDNA haplogroup determination [6]. The HmtDB is a database of 1255 human mitochondrial genomes annotated with population and variability data that allows researchers to analyse their own mtDNA sequences and to automatically predict their haplogroups, yielding a list of haplogroups that match. However, haplogroup determination is carried out by comparing the complete mitochondrial genome sequences with the updated mtDNA haplogroup classification based on information of the coding-region single nucleotide polymorphisms (SNPs) for about $100 \mathrm{mtDNA}$ haplogroups and subhaplogroups. Accordingly, haplogroup estimation using the HmtDB would be useful for researchers dealing with complete mitochondrial genome sequences, but would not be applicable to the detection of possible errors when researchers have only mtDNA control-region sequences.

As for the database, the EDNAP (European DNA Profiling Group) mtDNA Population Database (EMPOP) is notable because it was established through a collaborative project in order to provide reliable frequency estimates for routine forensic casework [7]. The EMPOP was designed to be a high-quality, Web-based mtDNA database where primary sequence-lane data are permanently linked to compiled sequences, and phylogenetic quality control analyses are applied to data to check for errors [8]. Currently, the EMPOP contains 5173 high-quality mtDNA haplotypes that are classified into sub-Saharan African, West Eurasian, East Asian and Southeast Asian metapopulations, and thus enables users to assess the rarity of a forensic mtDNA haplotype in various populations. However, due to somewhat narrow query options and inconvenient method used to display the results, its query tool appears to be optimized for calculating frequency estimates for random matches rather than for database screening to detect possible mtDNA errors. Also, the EMPOP does not allow batch analyses. In addition to the accessibility of high-quality databases to generate reliable frequency estimates, the addition of batch analysis of mtDNA sequence data and the construction of a user's database would be greatly beneficial to forensic staff.

Here we present a Web-based bioinformatics resource called mtDNAmanager that provides a convenient interface supporting the management and quality analysis of mtDNA sequence data. The mtDNAmanager performs computations on mtDNA control-region sequences for estimating the most-probable mtDNA haplogroups, and retrieves similar sequences from a selected database. The aims of mtDNAmanager are (1) to allow researchers to automatically estimate the most-probable mtDNA haplogroups of their mtDNA control-region sequences, (2) to facilitate database screening with improved query tools and (3) to provide researchers with a convenient interface for managing and analysing their own data in batch mode. A query system in mtDNAmanager allows researchers to find sequences in the database that include queried nucleotide polymorphisms or to exhibit matches from either a selected population or the entire population. Inputted mtDNA sequences, which are either partial or whole mtDNA control-region sequences, are entered as differences relative to the revised Cambridge Reference Sequence (rCRS) [9]. During sequence searches, mtDNAmanager automatically estimates corresponding haplogroups for submitted data and calculates frequency estimates for random matches. Retrieved sequences are also annotated with the estimated haplogroup affiliation to highlight nucleotide polymorphisms that are specific to a certain group of mtDNA haplotypes. This application provides the first publicly available interface to automatically estimate the most-probable mtDNA haplogroups according to control-region mutation motifs, thereby facilitating data comparisons from a phylogenetic perspective.

\section{Implementation}

The mtDNAmanager interface was designed to allow researchers to easily query the database and immediately view results on a single page. The mtDNAmanager Web 
interfaces were implemented using PHP and Asynchronous JavaScript and XML (AJAX). AJAX makes Web pages more responsive by exchanging small amounts of data with a server in the background, and thus mtDNAmanager Web pages do not have to be reloaded after each user request. This design aimed at increasing the interactivity, speed, functionality and usability of mtDNAmanager. The mtDNAmanager system is optimized for Internet Explorer version 6.0 or later.

mtDNAmanager has a multithreaded and multiuser SQL database management system designed and implemented using MySQL. The mtDNAmanager database currently comprises seven tables containing human mtDNA control-region sequences, data related to the samples and results of haplogroup estimation obtained by the mtDNA haplogroup-estimating resource that runs automatically (Figure 1).
The most-probable haplogroup of a given mtDNA sequence is estimated using a mathematical algorithm based on propositional logic via hierarchical verification of the presence or absence of haplogroup-specific diagnostic mutations. For that purpose, reliable controlregion mutation motifs (strings of characteristic/diagnostic mutations shared by descent) for the assignment of more than $400 \mathrm{mtDNA}$ haplogroups and subhaplogroups were first identified based on well-characterized mtDNA phylogenies (see the list of mutation motifs at http:// mtmanager.yonsei.ac.kr/help/MutationMotifs.pdf] [1049]. Mutation motifs of most of the haplogroups could immediately be read from the mtDNA tree. However, since each position of the mutation motif displays different mutation rates and homoplasy mutations are also observed in multiple motifs, individual diagnostic positions were weighted in each haplogroup background. To this end, polymorphisms of representative haplotypes

\begin{tabular}{|c|c|c|c|c|c|c|c|}
\hline \multicolumn{2}{|r|}{ user } & \multicolumn{2}{|c|}{ sample_group } & \multicolumn{2}{|r|}{ sample } & \multicolumn{2}{|r|}{ sequence } \\
\hline \multirow[t]{6}{*}{ PK } & email & PK & group id & PK & sample_id & PK & seq_id \\
\hline & $\begin{array}{l}\text { name } \\
\text { name2 } \\
\text { company } \\
\text { dept }\end{array}$ & & $\begin{array}{l}\text { group_name } \\
\text { metapop } \\
\text { subpop } \\
\text { des }\end{array}$ & & $\begin{array}{l}\text { sample_no } \\
\text { des } \\
\text { exp_hg } \\
\text { est_hg }\end{array}$ & FK1 & $\begin{array}{l}\text { cell_no } \\
\text { ins } \\
\text { code } \\
\text { sample_id }\end{array}$ \\
\hline & postcode & & hv2 & FK1 & group_id & & \\
\hline & city & & hv3 & & & & \\
\hline & country & & $\mathrm{cr}$ & & & & \\
\hline & password & FK1 & owner & & & & \\
\hline
\end{tabular}

\begin{tabular}{|l|l|}
\hline \multicolumn{2}{|c|}{ hg_order } \\
\hline & $\begin{array}{l}\text { metapop } \\
\text { s_order }\end{array}$ \\
\hline
\end{tabular}

\begin{tabular}{|l|l|}
\hline \multicolumn{2}{|c|}{ exp_hg } \\
\hline & \\
\hline $\begin{array}{l}\text { label } \\
\text { level } \\
\text { sequence }\end{array}$ \\
\hline
\end{tabular}

\begin{tabular}{|l|l|}
\hline \multicolumn{2}{|c|}{ est_hg } \\
\hline & \\
\hline $\begin{array}{l}\text { label } \\
\text { level } \\
\text { sequence }\end{array}$ \\
\hline
\end{tabular}

Figure I

Relational database structure of mtDNAmanager. 
allocated to the corresponding haplogroup or subhaplogroup were screened against other closely related mtDNA haplotypes. According to the mutation stability and specificity in each haplogroup background, individual diagnostic sites were classified into clearer diagnostic mutations and their accompanying mutations. To obtain mutation frequencies, published high-quality data were mostly used, but the data found on Internet resources were also used. The clear key diagnostic mutations of a certain haplogroup could be a single mutation or a combination of multiple mutations. They were selected from the polymorphic sites observed in every haplotype of the corresponding haplogroup (100\% specificity) and mostly were not shared with any other haplogroups. On the other hand, accompanying mutations are also observed in almost every haplotype of the corresponding haplogroup (>95\% specificity), but could include polymorphic sites observed in another haplogroups. Based on these haplogroup-specific mutation motifs, the bioinformatics tools of mtDNAmanager designates the "expected haplogroup" when a queried data sequence possesses clear diagnostic mutations, and designates the "estimated haplogroup" when the data indicate the presence of accompanying mutations additional to the clear diagnostic mutations.

This haplogroup-estimation workflow gives priority to certain haplogroups according to their degree of specificity to corresponding population groups. Therefore, the bioinformatics tools of mtDNAmanager have a hierarchy consisting of several levels of mutation motifs. Since all of the key diagnostic mutations equally have very high specificity for their corresponding haplogroups or subhaplogroups, the levels of mutation motifs in haplogroup designation were determined by the mutation stability of each mutation motif. Therefore, within a certain haplogroup branch, subhaplogroups have a higher priority than their root haplogroups, and among haplogroups of different branches, haplogroups associated with key diagnostic sites that have a lower mutation frequency in a certain population group have a higher priority. However, since mutation frequencies and specificities differ among population groups, the order of haplogroup designations in a hierarchical analysis of diagnostic mutations varied with the population group represented in the queried sequence. In addition, for two different haplogroups with identical key diagnostic mutations, the haplogroup with the highest prevalence in a certain population group has designation priority.

The data set used to test the bioinformatics tools of $\mathrm{mtD}$ NAmanager contained more than 5000 mtDNA controlregion sequences whose haplogroup affiliations were available from previous publications or on the Internet. Actually, the bioinformatics tools of mtDNAmanager allowed more than $98 \%$ of mtDNA to be allocated to an appropriate mtDNA haplogroup or subhaplogroup. For data sets with haplogroup information confirmed by coding-region SNPs, relatively good concordance was also observed between the expected and reference haplogroups (e.g. the concordance of 140 African Americans, 273 Austrians and 593 Koreans was 99.3\%, 99.3\% and $99.7 \%$, respectively) $[34,50,51]$.

\section{Results \\ Content and design of the open database}

The current open database of mtDNAmanager contains $7090 \mathrm{mtDNA}$ control-region sequences grouped in the following five subsets: African $(n=1388)$, West Eurasian $(n=2857)$, East Asian $(n=1557)$, Oceanian and Admixed $(n=1288)$ [50-62]. All of the mtDNA control-region sequences were annotated with estimated haplogroup affiliations using the mtDNAmanager bioinformatics tools. In cases where a data sequence had been assigned to a certain haplogroup in a previous study, relevant haplogroup information is provided in the output results.

The query system of mtDNAmanager retrieves sequences that include queried nucleotide polymorphisms from a selected population or the entire population group of its open database by default (exchangeable with the "include" or "match" settings). Since any combination of nucleotide polymorphisms or any partial control-region sequences can be analysed using the include setting, $\mathrm{mtD}$ NAmanager is very useful for analysing partial sequences or comparing similar sequences that share the same nucleotide polymorphisms (Figure 2). With the alternative setting of match, mtDNAmanager also searches sequences that match the queried sequence data from the database. mtDNAmanager provides match options to select specific regions to be analysed [HV1 (hypervariable region 1): np 16024-16365; HV2: np 73-340; HV3: np 438-576; and control-region: np 16024-16569, np 1-576], ignore heteroplasmic insertions in poly C-stretches and permit mismatches in order to overcome differences in data reporting between laboratories due to variability in the analysis region, ambiguities with respect to mtDNA nomenclature and different treatment of length variants (insertion/deletion).

The frequency of a queried nucleotide polymorphism or sequence is estimated from the number of times $(x)$ that it appears in a database of size $n$ (that is generally known as the counting method) while taking into account uncertainty due to sampling errors. This frequency is therefore estimated as $(x+2) /(n+2)[63]$, and is represented as the "match probability".

\section{Design of user database}

Upon registration, mtDNAmanager provides Web interfaces through which users can submit and store their data 


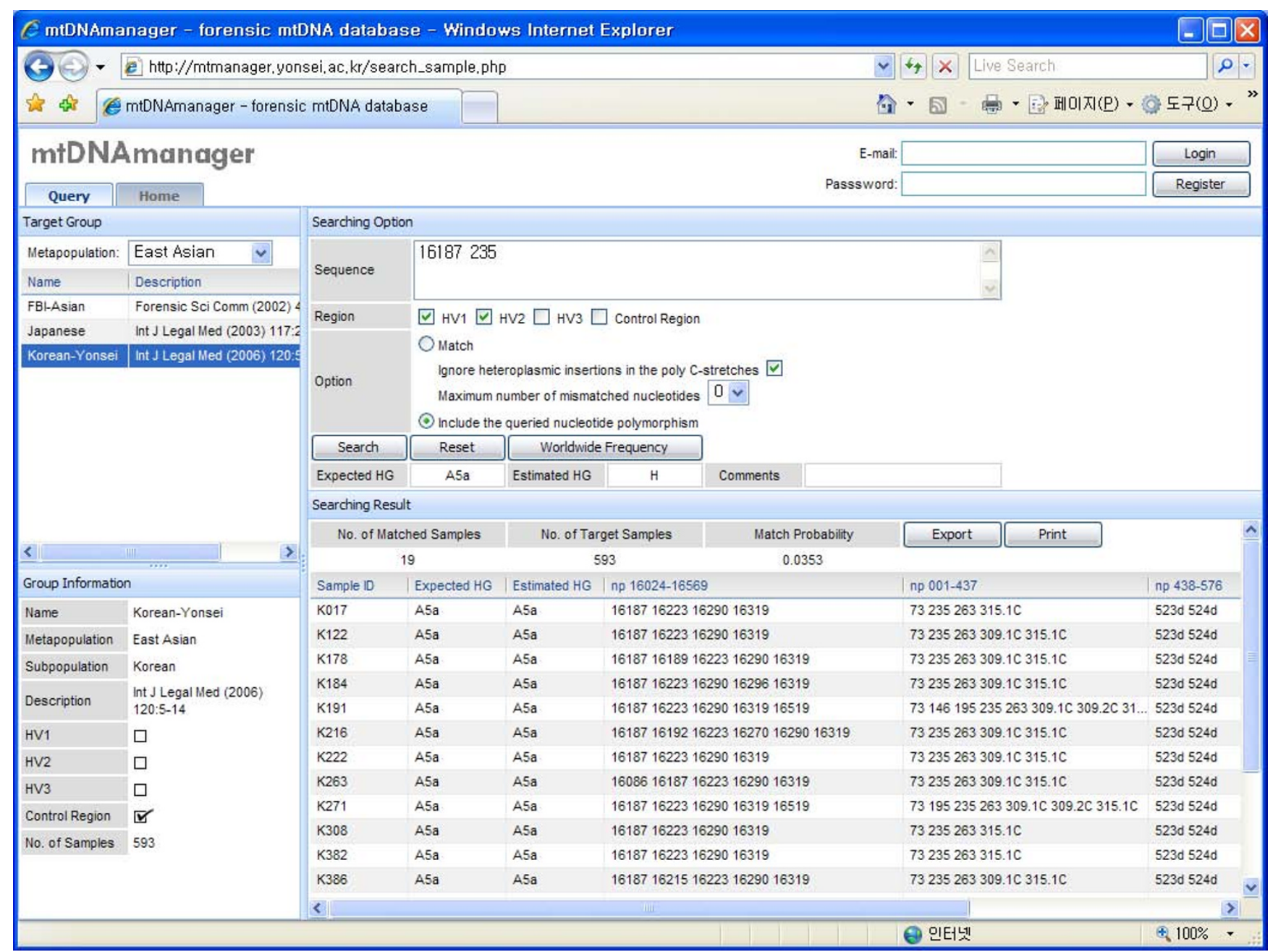

\section{Figure 2}

Query page of the mtDNAmanager. The query system - using the include setting by default - retrieves sequences that include the queried nucleotide polymorphisms from a chosen population or the entire population group of its open database. The results are displayed on the same page that the query was entered, and while displaying retrieved sequences, mtDNAmanager shows frequency estimates for random matches from a selected group and automatically estimated haplogroup affiliations for both submitted data and retrieved sequences.

in batch mode and search for sequences that show a match or include queried nucleotide polymorphisms from their databases as well as mtDNAmanager's open database. The sample system allows users to submit their own data in batch mode and store data in groups while simultaneously characterizing them by the automatically running haplogroup-estimating workflow (Figure 3A). The match system permits cross-matches of all sequence data between two selected groups as well as the retrieval of matched sequences for a sample of the user's database from their own database or mtDNAmanager's open database, which will facilitate casework in disasters involving many individuals (Figure 3B). In addition, the query system enables users to search sequences that show a match or include the queried nucleotide polymorphisms from their own databases or mtDNAmanager's open database, thus assisting the analysis of the increasing amount of mtDNA data available worldwide.

\section{Input}

Input queries are entered as differences relative to the rCRS according to ISFG (International Society for Forensic Genetics) guidelines [64]. When a difference between sequence data and the rCRS is observed, only the site (which has a designated number) and nucleotide differing from the reference standard are recorded (e.g. "73G"). Insertions are recorded by first noting the site immediately 5 ' to the insertion followed by a decimal point and a "1" (for the first insertion), a "2" (if there is a second insertion) and so on, and then the nucleotide that is inserted is 


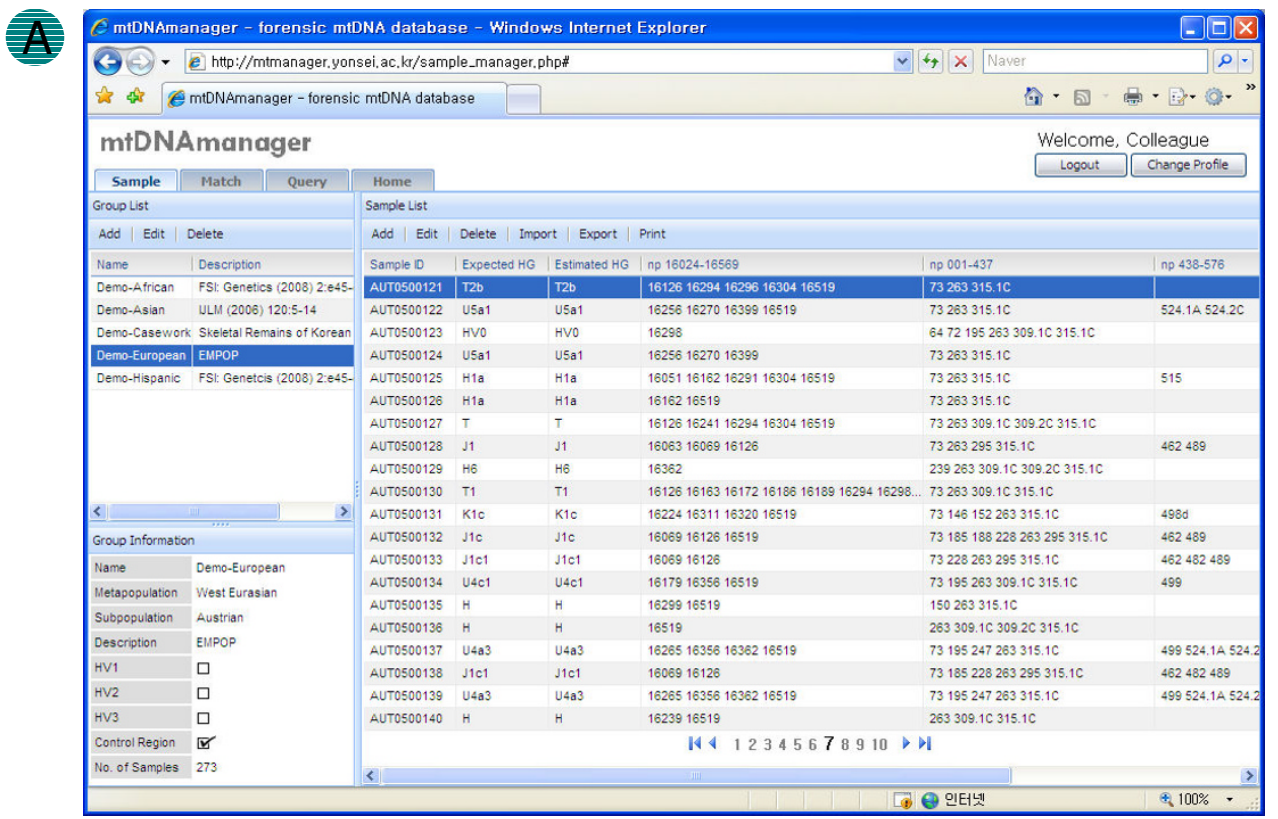

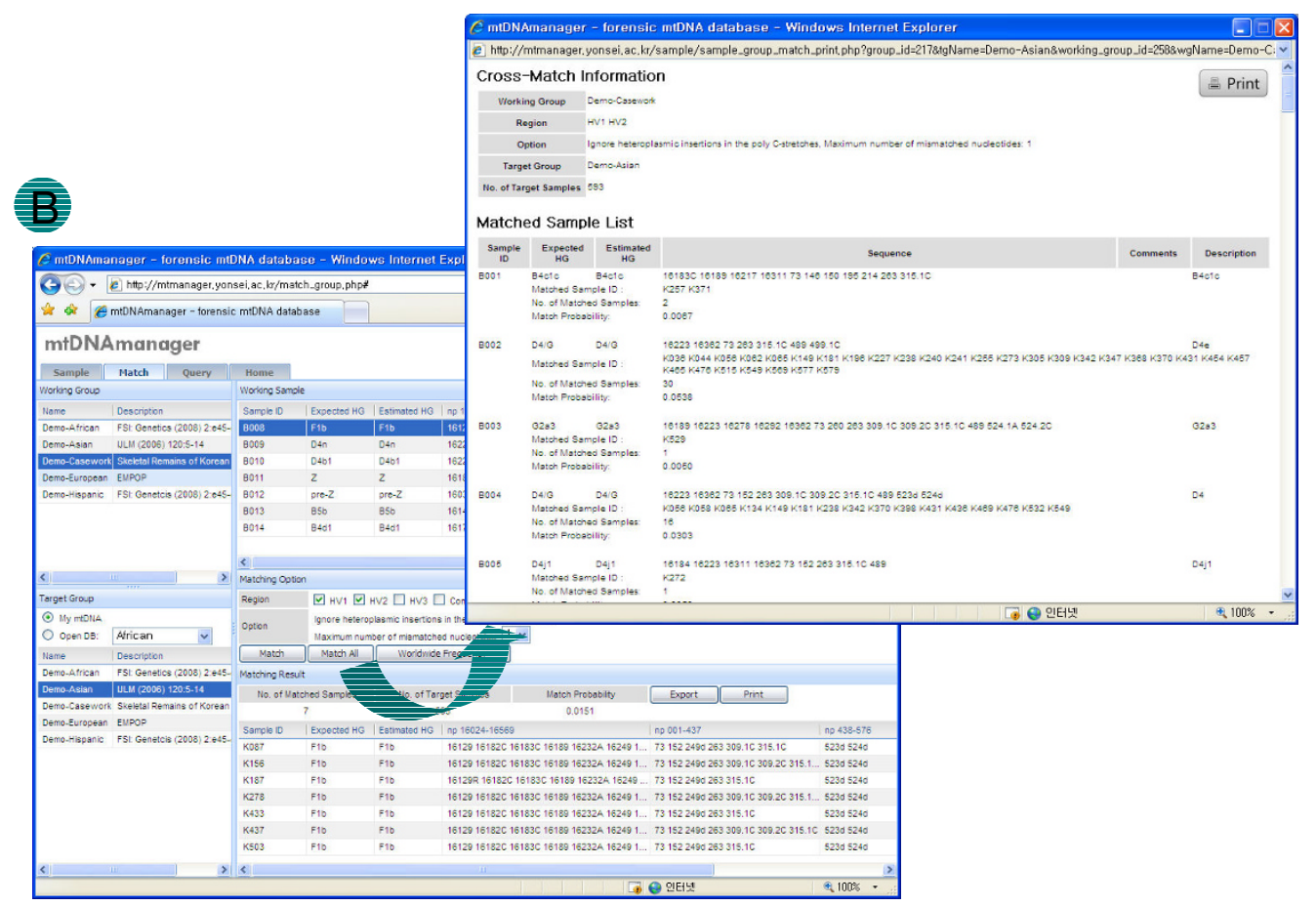

Figure 3

Sample and match pages of the $m$ tDNAmanager. Upon registration, mtDNAmanager provides Web interfaces that allow users to submit and store their own data in batch mode and search sequences that show a match or include queried nucleotide polymorphisms from their own databases as well as mtDNAmanager's open database. (A) The sample system allows users to manage and analyse large amounts of data in batch mode. Data are characterized whilst being imported by the automatically running haplogroup-estimating workflow, and accordingly, each sample is annotated with the most-probable mtDNA haplogroup (both expected and estimated haplogroups). (B) The match system permits cross-matching of all sequence data between two selected groups as well as retrieval of matched sequences for a sample of the own database of the user or mtDNAmanager's open database. Clicking the "Match All" button will display cross-matched results in a new pop-up window. 
recorded (e.g. "315.1C"). Deletions are recorded by listing the missing site followed by a "d" (i.e. "249d"). For convenience, transition mutations can be recorded by listing the site and omitting the indication of the nucleotide difference. However, transversion mutations are recorded in every case (e.g. "73" versus "73C") in which the nucleotide differs from the reference standard. Polymorphic sites can be separated using a space, return or comma character. Sequence searches are allowed to show matches even when no data (i.e. no differences relative to the rCRS) have been submitted, since some Europeans possess mtDNA control-region sequences identical to the rCRS. The frequencies of nucleotide polymorphisms that are identical to the rCRS can also be obtained by entering the site and nucleotide polymorphisms of the rCRS or by entering the site with "=" (e.g. "73A" and "73=") using the include setting.

- Input sequence example 1: 16304C 73G 249d 263G 315.1C

- Input sequence example 2: 1630473 249d 263 315.1C

To import data through the sample system in batch mode, the sample group should first be generated by the user. User-defined sample groups are added to the group list by clicking the "Add" button and entering their names and properties. Then, batch input files are prepared in a text file to be imported into a specific, user-defined group. Input files are initially prepared as Excel files that contain both the mtDNA sequence data and descriptions of the properties of the data (see examples at http://mtman ager.yonsei.ac.kr/help/Examples.xls). The mtDNA sequence data are entered using the same method as input queries. The Excel file is then saved as a text file (separated by tabs) that is imported to a specific user-defined group of the sample system. Input sequences can also be uploaded one by one using the "Add" button on the sample list.

\section{Output}

Results from mtDNAmanager are displayed on the same page on which the query was submitted (Figure 2). While showing retrieved sequences, mtDNAmanager shows frequency estimates for random matches from a selected group and the automatically estimated haplogroup affiliations for submitted data. Queried nucleotide polymorphisms that are either identical to the rCRS or entered as IUPAC (International Union of Pure and Applied Chemistry) codes for point heteroplasmy are indicated as such under "Comments". Frequency estimates for all of the population groups in the database can be obtained by clicking the "Worldwide Frequency" button, and the cross-match result can be obtained by clicking the "Match All" button. The retrieved sequences are displayed with estimated haplogroup affiliations (both expected and estimated haplogroups), nucleotide polymorphisms and, if available, the haplogroup affiliations obtained from previous reports. Therefore, $\mathrm{mtDNAmanager} \mathrm{should} \mathrm{facilitate}$ the comparison of sequences that share the same nucleotide polymorphisms from a phylogenetic perspective. In addition to the Web-page presentation tools, retrieved sequences can be exported as an Excel file for user convenience.

\section{Discussion}

The mtDNAmanager can be used to manage large amounts of mtDNA data as well as to estimate the quality of mtDNA data and compare such data with similar sequences from a phylogenetic perspective. The application provides systematic routines for error detection and strategies for screening mtDNA databases by enabling researchers to automatically estimate the most-probable mtDNA haplogroups and search the database with two alternative settings (include and match).

In particular, the phased designation of haplogroups (i.e. expected haplogroups and estimated haplogroups) facilitates systematic error detection by allowing the respective confirmation of the presence of clearer key diagnostic mutations and accompanying mutations. Specifically, if a certain mtDNA sequence was annotated with the same expected and estimated haplogroups, this means that the sequence possessed the complete mutation motif for the corresponding haplogroup. Likewise, if a sequence was annotated with only the expected haplogroup, this suggests a lack of accompanying mutations for the expected haplogroup, which was determined by the presence of key diagnostic mutations (Figure 4A). From an mtDNA phylogenetic perspective, this would mean that a given mtDNA haplotype is located at a previously unsampled interior node of the tree such as a back mutation [4]. Accordingly, in this case, it would be necessary to recheck the entire set of haplogroup-specific mutation sites in a given sequence data. More importantly, data without both of the haplogroup affiliations or that showed discordance between expected and estimated haplogroups would also imply a need to recheck the sequence for possible errors due to contamination or a sample mix-up during the sequencing and documentation process (Figure 5). Since mtDNA haplotypes that could only be obtained from separate amplifications of several smaller fragments - such as those found in highly degraded samples - are prone to these errors, using mtDNAmanager to confirm the absence of these errors after data generation will help to authenticate the sequence data in highly degraded samples. For user convenience, currently identified haplogroup-specific control-region mutation motifs for more than 400 haplogroups are available on the mtDNAmanager home page. From a phylogenetic perspective, mtDNA 


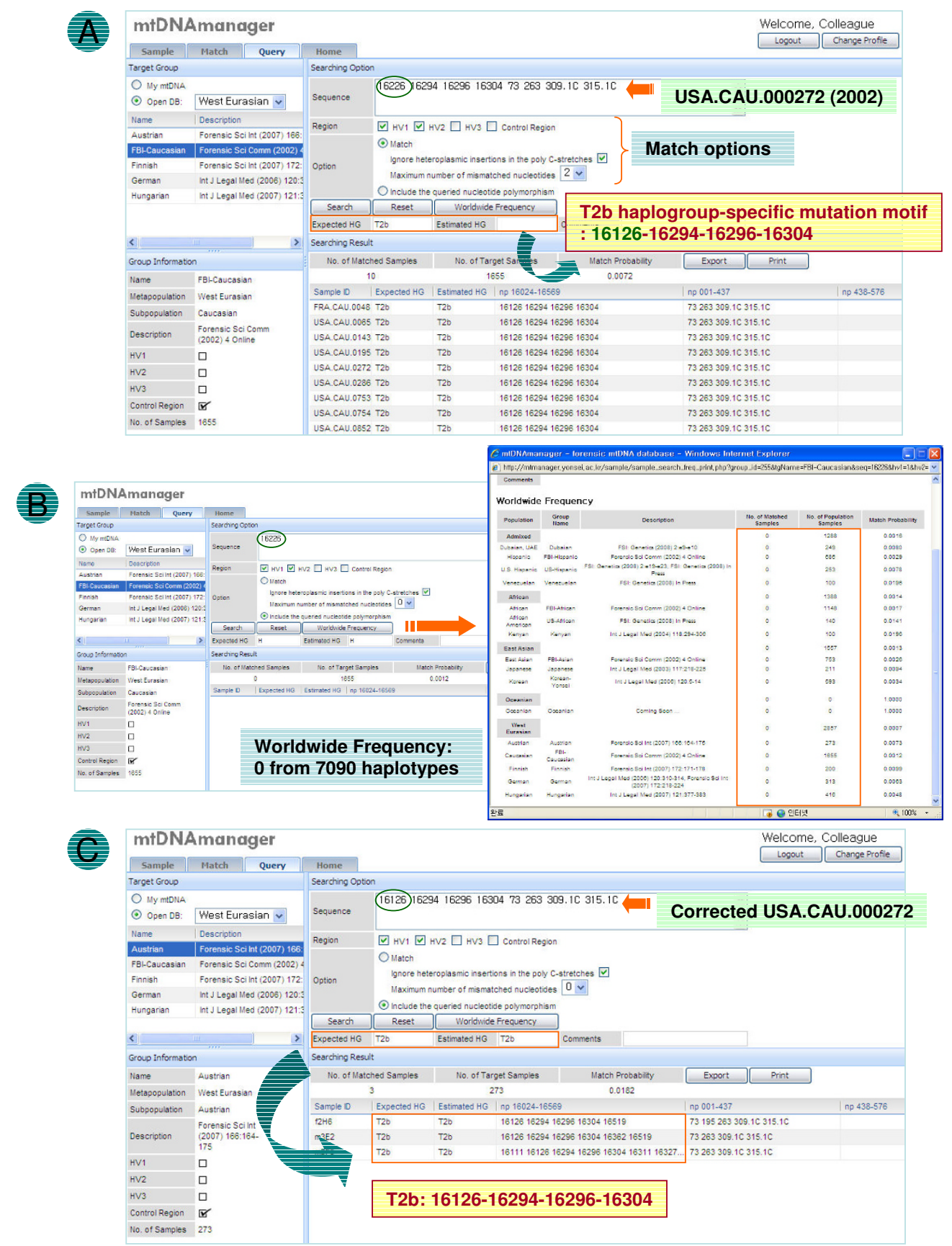

\section{Figure 4}

An example of clerical error detection using mtDNAmanager. (A) Using the match setting, USA.CAU.000272 [I,52] was analysed with the option that permits mismatch. The results showed that the sequence had no match with European populations, but the retrieved similar sequences containing mismatches all belonged to the T2b haplogroup. In addition, the original sequence was annotated with only the expected haplogroup, T2b. It was suspected that the mutation at 16226 resulted from a clerical error because the mutation motif for the T2b haplogroup suggested that the sequence lacks the 16126 mutation. (B) By clicking "Worldwide Frequency", the rarity of the 16226 mutation was investigated and the results showed that none of the $7090 \mathrm{mtDNA}$ sequences bears this mutation. (C) The corrected sequence [52] was annotated with both the expected and estimated haplogroups of $\mathrm{T} 2 \mathrm{~b}$. 


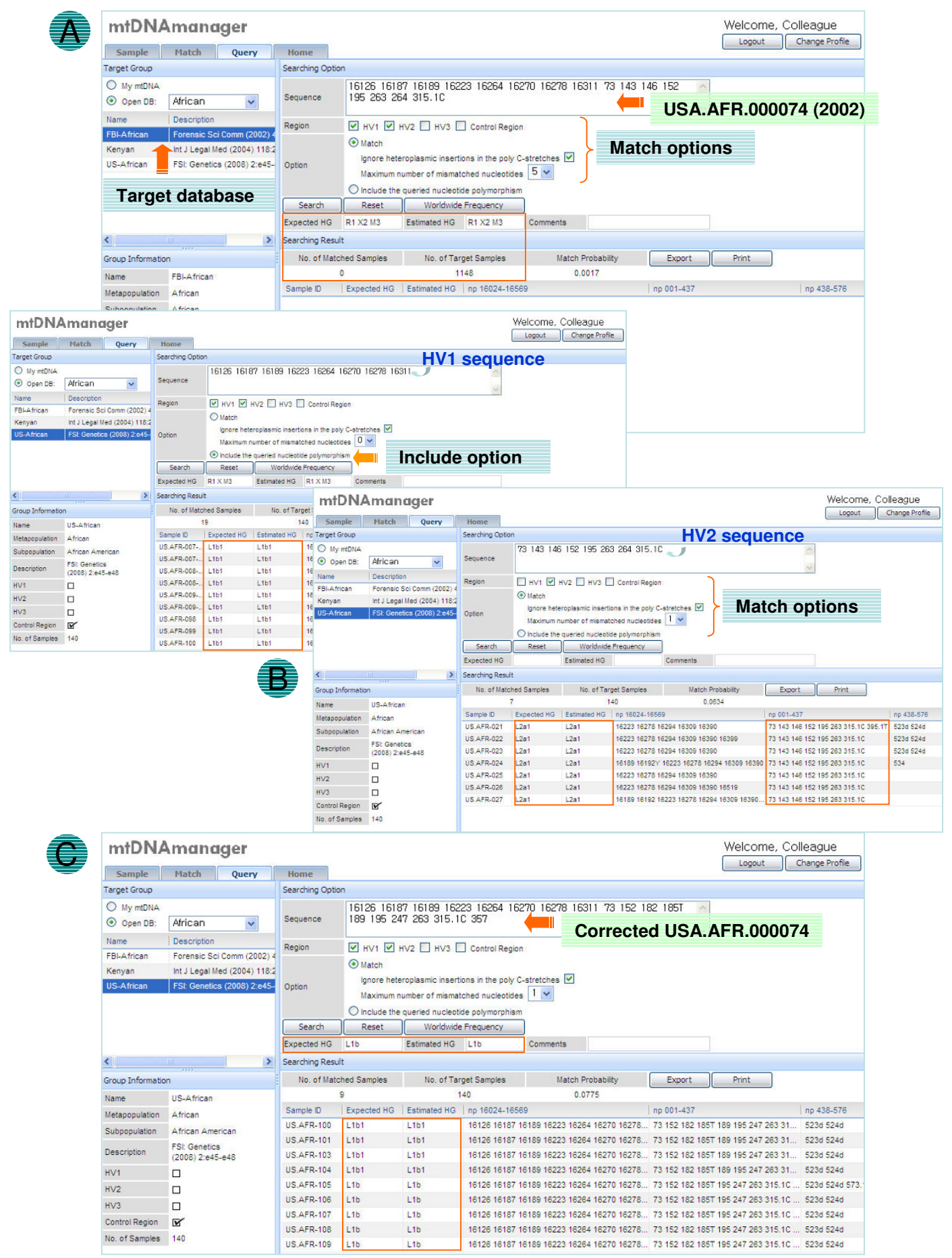

\section{Figure 5}

An example of artificial recombination error detection using mtDNAmanager. (A) USA.AFR.000074 [52,65] did not show a match with African populations or affiliations with either haplogroup. (B) Since the data set was known to be prepared from separate amplification of hypervariable regions, a possible artificial recombination was checked using query tools. The results showed that the HVI sequence was only evident in the LIbI haplogroup, and the HV2 sequence was only evident in the L2a I haplogroup. (C) The corrected sequence [52] was annotated with both the expected and estimated haplogroups of LIb. 
control-region sequence information might not be sufficient for assigning certain mtDNAs into respective haplogroups as reliably as the coding-region information, but the control-region mutation motifs of mtDNAmanager will at least suggest candidate sites or regions that need reinvestigation.

Frequency estimates and sequences retrieved using the include setting indicate the rarity of a nucleotide polymorphism in databases and show similar sequences that share queried nucleotide polymorphisms. Accordingly, mtDNAmanager can reveal unusual, private mutations (Figure $4 \mathrm{~B}$ ) and suggest a subset of potentially close relatives annotated with estimated haplogroup affiliations even when the haplogroup estimation of a queried sequence data fails (Figure 5B). This will highlight nucleotide polymorphisms that are specific to the retrieved group of mtDNA haplotypes and help to distinguish sites that should be analysed further. In other cases, retrieved sequences with estimated haplogroup affiliations will contribute to completing and refining haplogroup classification by revealing mutation sites that are specific to a new branch of phylogeny. Therefore, to improve mtDNA database screening, we will continue to collect and integrate high-quality mtDNA control-region sequence data that are publicly available.

In addition, mtDNAmanager provides a convenient interface that allows users to construct and analyse their own databases. Therefore, users can collect high-quality data from public databases (e.g. EMPOP) or direct sequencing results to construct their own databases. mtDNAmanager will suggest the most-probable mtDNA haplogroups for all of the sequences in the database, allowing users to also easily estimate the quality of the database. Researchers will therefore be able to select and use the most appropriate database for error detection based on their own evaluation of the quality of the available databases.

\section{Conclusion}

The mtDNAmanager supports the management and quality analysis of mtDNA sequence data using software that performs computations on mtDNA control-region sequences for estimating the most-probable mtDNA haplogroups. mtDNAmanager will help in checking the quality of data and facilitate data comparisons from a phylogenetic perspective by displaying information - estimated haplogroup affiliations and nucleotide polymorphisms - of all sequences on a single page. In addition, mtDNAmanager provides researchers with a convenient interface for managing and analysing their own data in batch mode. Therefore, this tool could be very useful for population, medical and forensic studies that involve mtDNA analysis.

\section{Availability and requirements}

Project name: A Web-based tool for the management and quality analysis of mitochondrial DNA control-region sequences

Project home page: http://mtmanager.yonsei.ac.kr

Operating system(s): Microsoft Windows

Programming language: PHP, Asynchronous JavaScript and XML

Other requirements: Optimized for Internet Explorer version 6.0 or later

Any restrictions to use by non-academics: None

\section{Authors' contributions}

KJS initiated the concept of mtDNAmanager. IS and KJS developed the major modules of mtDNAmanager, and IS, HYL and KJS designed the graphical user interface. KJS reviewed and tested the software. HYL wrote this manuscript, and EH, SBC and WIY helped to draft it.

\section{Acknowledgements}

This work was supported by a Korean Science and Engineering Foundation (KOSEF) grant funded by the Korea government (MEST) (No.

MI 0740030002-07N4003-002 10), and grants from the Ministry of National Defense Agency for Killed In Action Recovery and Identification (MAKRI).

\section{References}

I. Bandelt HJ, Salas A, Bravi C: Problems in FBI mtDNA database. Science 2004, 305: | 402-1404.

2. Budowle B, Polanskey D: FBI mtDNA database: a cogent perspective. Science 2005, 307:845-847.

3. Salas A, Carracedo A, Macaulay V, Richards M, Bandelt HJ: A practical guide to mitochondrial DNA error prevention in clinical, forensic, and population genetics. Biochem Biophys Res Commun 2005, 335:891-899.

4. Bandelt HJ, Lahermo P, Richards M, Macaulay V: Detecting errors in mtDNA data by phylogenetic analysis. Int J Legal Med 200I, I I 5:64-69.

5. Bandelt HJ, Quintana-Murci L, Salas A, Macaulay V: The fingerprint of phantom mutations in mitochondrial DNA data. Am J Hum Genet 2002, 7 I: II50-II60.

6. Attimonelli M, Accetturo M, Santamaria M, Lascaro D, Scioscia G, Pappadà G, Russo L, Zanchetta L, Tommaseo-Ponzetta M: HmtDB, a human mitochondrial genomic resource based on variability studies supporting population genetics and biomedical research. BMC Bioinformatics 2005, 6:S4.

7. The European DNA Profiling Group (EDNAP) MtDNA Population Database (EMPOP) [http://www.empop.org]

8. Parson W, Dür A: EMPOP-A forensic mtDNA database. Forensic Sci Int Gene 2007, 1:88-92.

9. Andrews RM, Kubacka I, Chinnery PF, Lightowlers RN, Turnbull DM, Howell N: Reanalysis and revision of the Cambridge reference sequence for human mitochondrial DNA. Nat Genet 1999, 23:147.

10. Macaulay V, Richards M, Hickey E, Vega E, Cruciani F, Guida V, Scozzari R, Bonné-Tamir B, Sykes B, Torroni A: The emerging tree of West Eurasian mtDNAs: a synthesis of control-region sequences and RFLPs. Am J Hum Genet 1999, 64:232-249.

1I. Helgason A, Hickey E, Goodacre S, Bosnes V, Stefánsson K, Ward R, Sykes B: mtDNA and the islands of the North Atlantic: esti- 
mating the proportions of Norse and Gaelic ancestry. Am J Hum Genet 200I, 68:723-737.

12. Kivisild T, Tolk HV, Parik J, Wang Y, Papiha SS, Bandelt HJ, Villems R: The emerging limbs and twigs of the East Asian mtDNA tree. Mol Biol Evol 2002, 19:1737-175I.

13. Salas A, Richards M, De la Fe T, Lareu MV, Sobrino B, Sánchez-Diz P, Macaulay V, Carracedo A: The making of the African mtDNA landscape. Am J Hum Genet 2002, 71:1082-IIIII.

14. Kong QP, Yao YG, Liu M, Shen SP, Chen C, Zhu CL, Palanichamy MG Zhang YP: Mitochondrial DNA sequence polymorphisms of five ethnic populations from northern China. Hum Genet 2003 , I I 3:391-405.

15. Kong QP, Yao YG, Sun C, Bandelt HJ, Zhu CL, Zhang YP: Phylogeny of East Asian mitochondrial DNA lineages inferred from complete sequences. Am J Hum Genet 2003, 73:67I-676.

16. Reidla M, Kivisild T, Metspalu E, Kaldma K, Tambets K, Tolk HV, Parik J, Loogväli EL, Derenko M, Malyarchuk B, Bermisheva M, Zhadanov S, Pennarun E, Gubina M, Golubenko M, Damba L, Fedorova S, Gusar V, Grechanina E, Mikerezi I, Moisan JP, Chaventré A, Khusnutdinova E, Osipova L, Stepanov V, Voevoda M, Achilli A, Rengo C, Rickards O, De Stefano GF, Papiha S, Beckman L, Janicijevic B, Rudan P, Anagnou $\mathrm{N}$, Michalodimitrakis E, Koziel S, Usanga E, Geberhiwot T, Herrnstadt C. Howell N, Torroni A, Villems R: Origin and diffusion of mtDNA haplogroup X. Am J Hum Genet 2003, 73: I I78-I I 90.

17. Achilli A, Rengo C, Magri C, Battaglia V, Olivieri A, Scozzari R, Cruciani F, Zeviani M, Briem E, Carelli V, Moral P, Dugoujon JM, Roostalu U, Loogväli EL, Kivisild T, Bandelt HJ, Richards M, Villems R, Santachiara-Benerecetti AS, Semino O, Torroni A: The molecular dissection of mtDNA haplogroup $H$ confirms that the FrancoCantabrian glacial refuge was a major source for the European gene pool. Am J Hum Genet 2004, 75:910-918.

18. Kivisild T, Reidla M, Metspalu E, Rosa A, Brehm A, Pennarun E, Parik J, Geberhiwot T, Usanga E, Villems R: Ethiopian mitochondrial DNA heritage: tracking gene flow across and around the gate of tears. Am J Hum Genet 2004, 75:752-770.

19. Loogväli EL, Roostalu U, Malyarchuk BA, Derenko MV, Kivisild T, Metspalu E, Tambets K, Reidla M, Tolk HV, Parik J, Pennarun E, Laos S, Lunkina A, Golubenko M, Barac L, Pericic M, Balanovsky OP, Gusar V, Khusnutdinova EK, Stepanov V, Puzyrev V, Rudan P, Balanovska EV, Grechanina E, Richard C, Moisan JP, Chaventre A, Anagnou NP, Pappa KI, Michalodimitrakis EN, Claustres M, Golge M, Mikerezi I, Usanga $E$, Villems R: Disuniting uniformity: a pied cladistic canvas of mtDNA haplogroup $\mathbf{H}$ in Eurasia. Mol Biol Evol 2004 21:2012-2021

20. Metspalu M, Kivisild T, Metspalu E, Parik J, Hudjashov G, Kaldma K, Serk P, Karmin M, Behar DM, Gilbert MT, Endicott P, Mastana S, Papiha SS, Skorecki K, Torroni A, Villems R: Most of the extant mtDNA boundaries in South and Southwest Asia were likely shaped during the initial settlement of Eurasia by anatomically modern humans. BMC Genet 2004, 5:26.

21. Palanichamy MG, Sun C, Agrawal S, Bandelt HJ, Kong QP, Khan F, Wang CY, Chaudhuri TK, Palla V, Zhang YP: Phylogeny of mitochondrial DNA macrohaplogroup $\mathbf{N}$ in India, based on complete sequencing: implications for the peopling of South Asia. Am J Hum Genet 2004, 75:966-978.

22. Quintana-Murci L, Chaix R, Wells RS, Behar DM, Sayar H, Scozzari R, Rengo C, Al-Zahery N, Semino O, Santachiara-Benerecetti AS, Coppa A, Ayub Q, Mohyuddin A, Tyler-Smith C, Qasim Mehdi S, Torroni A, McElreavey K: Where west meets east: the complex mtDNA landscape of the southwest and Central Asian corridor. Am J Hum Genet 2004, 74:827-845.

23. Salas A, Richards M, Lareu MV, Scozzari R, Coppa A, Torroni A Macaulay V, Carracedo A: The African diaspora: mitochondrial DNA and the Atlantic slave trade. Am J Hum Genet 2004 74:454-465.

24. Tanaka M, Cabrera VM, González AM, Larruga JM, Takeyasu T, Fuku $N$, Guo Ll, Hirose R, Fujita $Y$, Kurata M, Shinoda K, Umetsu K, Yamada Y, Oshida Y, Sato Y, Hattori N, Mizuno Y, Arai Y, Hirose N, Ohta S, Ogawa O, Tanaka Y, Kawamori R, Shamoto-Nagai M, Maruyama W, Shimokata $H$, Suzuki R, Shimodaira $H$ : Mitochondrial genome variation in eastern Asia and the peopling of Japan. Genome Res 2004, 14:1832-I850.

25. Yao YG, Kong QP, Wang CY, Zhu CL, Zhang YP: Different matrilineal contributions to genetic structure of ethnic groups in the silk road region in china. Mol Biol Evol 2004, 21:2265-2280.
26. Achilli A, Rengo C, Battaglia V, Pala M, Olivieri A, Fornarino S, Magri C, Scozzari R, Babudri N, Santachiara-Benerecetti AS, Bandelt HJ, Semino O, Torroni A: Saami and Berbers - an unexpected mitochondrial DNA link. Am J Hum Genet 2005, 76:883-886.

27. Friedlaender J, Schurr T, Gentz F, Koki G, Friedlaender F, Horvat G, Babb P, Cerchio S, Kaestle F, Schanfield M, Deka R, Yanagihara R, Merriwether DA: Expanding Southwest Pacific mitochondrial haplogroups $\mathbf{P}$ and $\mathbf{Q}$. Mol Biol Evol 2005, 22:1506-1517.

28. Macaulay V, Hill C, Achilli A, Rengo C, Clarke D, Meehan W, Blackburn J, Semino O, Scozzari R, Cruciani F, Taha A, Shaari NK, Raja JM, Ismail P, Zainuddin Z, Goodwin W, Bulbeck D, Bandelt HJ, Oppenheimer S, Torroni A, Richards M: Single, rapid coastal settlement of Asia revealed by analysis of complete mitochondrial genomes. Science 2005, 308: $1034-1036$.

29. Merriwether DA, Hodgson JA, Friedlaender FR, Allaby R, Cerchio S, Koki G, Friedlaender JS: Ancient mitochondrial M haplogroups identified in the Southwest Pacific. Proc Natl Acad Sci USA 2005, 102:13034-13039.

30. Wen B, Li H, Gao S, Mao X, Gao Y, Li F, Zhang F, He Y, Dong Y, Zhang Y, Huang W, jin J, Xiao C, Lu D, Chakraborty R, Su B, Deka R, jin L: Genetic structure of Hmong-Mien speaking populations in East Asia as revealed by mtDNA lineages. Mol Biol Evol 2005, 22:725-734.

3I. Behar DM, Metspalu E, Kivisild T, Achilli A, Hadid Y, Tzur S, Pereira L, Amorim A, Quintana-Murci L, Majamaa K, Herrnstadt C, Howell N, Balanovsky O, Kutuev I, Pshenichnov A, Gurwitz D, Bonne-Tamir B, Torroni A, Villems R, Skorecki K: The matrilineal ancestry of Ashkenazi Jewry: portrait of a recent founder event. Am J Hum Genet 2006, 78:487-497.

32. Hill C, Soares P, Mormina M, Macaulay V, Meehan W, Blackburn J, Clarke D, Raja JM, Ismail P, Bulbeck D, Oppenheimer S, Richards M: Phylogeography and ethnogenesis of aboriginal Southeast Asians. Mol Biol Evol 2006, 23:2480-249I.

33. Kong QP, Bandelt HJ, Sun C, Yao YG, Salas A, Achilli A, Wang CY Zhong L, Zhu CL, Wu SF, Torroni A, Zhang YP: Updating the East Asian mtDNA phylogeny: a prerequisite for the identification of pathogenic mutations. Hum Mol Genet 2006, I 5:2076-2086.

34. Lee HY, Yoo JE, Park MJ, Chung U, Kim CY, Shin KJ: East Asian mtDNA haplogroup determination in Koreans: haplogrouplevel coding region SNP analysis and subhaplogroup-level control region sequence analysis. Electrophoresis 2006, 27:4408-44I8.

35. Olivieri A, Achilli A, Pala M, Battaglia V, Fornarino S, Al-Zahery N, Scozzari R, Cruciani F, Behar DM, Dugoujon JM, Coudray C, Santachiara-Benerecetti AS, Semino O, Bandelt HJ, Torroni A: The mtDNA legacy of the Levantine early Upper Palaeolithic in Africa. Science 2006, 314:1767-1770.

36. Pierson MJ, Martinez-Arias R, Holland BR, Gemmell NJ, Hurles ME, Penny $D$ : Deciphering past human population movements in Oceania: provably optimal trees of 127 mtDNA genomes. Mol Biol Evol 2006, 23:1966-1975.

37. Sun C, Kong QP, Palanichamy MG, Agrawal S, Bandelt HJ, Yao YG Khan F, Zhu CL, Chaudhuri TK, Zhang YP: The dazzling array of basal branches in the mtDNA macrohaplogroup $M$ from India as inferred from complete genomes. Mol Biol Evol 2006, 23:683-690

38. Thangaraj K, Chaubey G, Singh VK, Vanniarajan A, Thanseem I, Reddy AG, Singh L: In situ origin of deep rooting lineages of mitochondrial macrohaplogroup ' $M$ ' in India. BMC Genomics 2006, 7:151.

39. Thanseem I, Thangaraj K, Chaubey G, Singh VK, Bhaskar LV, Reddy $B M$, Reddy AG, Singh L: Genetic affinities among the lower castes and tribal groups of India: inference from $Y$ chromosome and mitochondrial DNA. BMC Genet 2006, 7:42.

40. Derenko M, Malyarchuk B, Grzybowski T, Denisova G, Dambueva I, Perkova M, Dorzhu C, Luzina F, Lee HK, Vanecek T, Villems R, Zakharov I: Phylogeographic analysis of mitochondrial DNA in northern Asian populations. Am J Hum Genet 2007, 81:1025-104I.

4I. Friedlaender JS, Friedlaender FR, Hodgson JA, Stoltz M, Koki G, Horvat G, Zhadanov S, Schurr TG, Merriwether DA: Melanesian mtDNA complexity. PLoS ONE 2007, 2:e248.

42. Hill C, Soares P, Mormina M, Macaulay V, Clarke D, Blumbach PB, Vizuete-Forster M, Forster P, Bulbeck D, Oppenheimer S, Richards 
M: A mitochondrial stratigraphy for island southeast Asia. Am J Hum Genet 2007, 80:29-43.

43. Hudjashov G, Kivisild T, Underhill PA, Endicott P, Sanchez JJ, Lin AA, Shen P, Oefner P, Renfrew C, Villems R, Forster P: Revealing the prehistoric settlement of Australia by $Y$ chromosome and mtDNA analysis. Proc Natl Acad Sci USA 2007, 104:8726-8730.

44. Reddy BM, Langstieh BT, Kumar V, Nagaraja T, Reddy AN, Meka A, Reddy AG, Thangaraj K, Singh L: Austro-Asiatic tribes of Northeast India provide hitherto missing genetic link between South and Southeast Asia. PLOS ONE 2007, 2:el I4I.

45. Roostalu U, Kutuev I, Loogväli EL, Metspalu E, Tambets K, Reidla M, Khusnutdinova EK, Usanga E, Kivisild T, Villems R: Origin and expansion of haplogroup $H$, the dominant human mitochondrial DNA lineage in West Eurasia: the Near Eastern and Caucasian perspective. Mol Biol Evol 2007, 24:436-448.

46. Achilli A, Perego UA, Bravi CM, Coble MD, Kong QP, Woodward SR, Salas A, Torroni A, Bandelt H]: The phylogeny of the four panAmerican MtDNA haplogroups: implications for evolutionary and disease studies. PLOS ONE 2008, 3:el764.

47. Malyarchuk B, Grzybowski T, Derenko M, Perkova M, Vanecek T, Lazur J, Gomolcak P, Tsybovsky I: Mitochondrial DNA phylogeny in Eastern and Western Slavs. Mol Biol Evol 2008, 25:165I- 1658.

48. Malyarchuk BA, Perkova MA, Derenko MV, Vanecek T, Lazur J, Gomolcak P: Mitochondrial DNA variability in Slovaks, with application to the Roma origin. Ann Hum Genet 2008, 72:228-40.

49. Soares $P$, Trejaut JA, Loo JH, Hill C, Mormina M, Lee CL, Chen YM, Hudjashov G, Forster P, Macaulay V, Bulbeck D, Oppenheimer S, Lin $M$, Richards MB: Climate change and post-glacial human dispersals in southeast Asia. Mol Biol Evol 2008, 25:1209-1218.

50. Brandstätter A, Niederstätter H, Pavlic M, Grubwieser P, Parson W: Generating population data for the EMPOP database-an overview of the mtDNA sequencing and data evaluation processes considering 273 Austrian control region sequences as example. Forensic Sci Int 2007, 166:164-175.

5I. Just RS, Diegoli TM, Saunier JL, Irwin JA, Parsons TJ: Complete mitochondrial genome sequences for 265 African American and U.S. "Hispanic" individuals. Forensic Sci Int Gene 2008, 2:e45-e48.

52. Monson KL, Miller KWP, Wilson MR, DiZinno JA, Budowle B: The mtDNA population database: an integrated software and database resource for forensic comparison. Forensic Sci Commun 2002, 4:.

53. Maruyama S, Minaguchi K, Saitou N: Sequence polymorphisms of the mitochondrial DNA control region and phylogenetic analysis of mtDNA lineages in the Japanese population. Int J Legal Med 2003, I I 7:2 I 8-225.

54. Brandstätter A, Peterson CT, Irwin JA, Mpoke S, Koech DK, Parson W, Parsons T]: Mitochondrial DNA control region sequences from Nairobi (Kenya): inferring phylogenetic parameters for the establishment of a forensic database. Int J Legal Med 2004, I I 8:294-306.

55. Brandstätter A, Klein R, Duftner N, Wiegand P, Parson W: Application of a quasi-median network analysis for the visualization of character conflicts to a population sample of mitochondrial DNA control region sequences from southern Germany (Ulm). Int J Legal Med 2006, I 20:3 I0-34.

56. Lee HY, Yoo JE, Park MJ, Chung U, Shin KJ: Mitochondrial DNA control region sequences in Koreans: identification of useful variable sites and phylogenetic analysis for mtDNA data quality control. Int $J$ Legal Med 2006, I 20:5-14.

57. Alshamali F, Brandstätter A, Zimmermann B, Parson W: Mitochondrial DNA control region variation in Dubai, United Arab Emirates. Forensic Sci Int Gene 2008, 2:e9-elO.

58. Hedman M, Brandstätter A, Pimenoff V, Sistonen P, Palo JU, Parson W, Sajantila A: Finnish mitochondrial DNA HVS-I and HVS-II population data. Forensic Sci Int 2007, 172:17I-178.

59. Irwin J, Egyed B, Saunier J, Szamosi G, O'callaghan J, Padar Z, Parsons TJ: Hungarian mtDNA population databases from Budapest and the Baranya county Roma. Int J Legal Med 2007, 121:377-383.

60. Tetzlaff S, Brandstätter A, Wegener R, Parson W, Weirich V: Mitochondrial DNA population data of HVS-I and HVS-II sequences from a northeast German sample. Forensic Sci Int 2007, I 72:218-224.

6I. Lander N, Rojas MG, Chiurillo MA, Ramirez JL: Haplotype diversity in human mitochondrial DNA hypervariable regions I-III in the city of Caracas (Venezuela). Forensic Sci Int Gene 2008 2:e6I-e64.

62. Saunier JL, Irwin JA, Just RS, O'Callaghan J, Parsons TJ: Mitochondrial control region sequences from a U.S. "Hispanic" population sample. Forensic Sci Int Gene 2008, 2:e 19-23.

63. Balding DJ, Nichols RA: DNA profile match probability calculation: how to allow for population stratification, relatedness, database selection and single bands. Forensic Sci Int 1994, 64: $125-140$

64. Carracedo A, Bär W, Lincoln P, Mayr W, Morling N, Olaisen B, Schneider P, Budowle B, Brinkmann B, Gill P, Holland M, Tully G, Wilson M: DNA commission of the international society for forensic genetics: guidelines for mitochondrial DNA typing. Forensic Sci Int 2000, I I 0:79-85.

65. Bandelt HJ, Salas A, Lutz-Bonengel S: Artificial recombination in forensic mtDNA population databases. Int J Legal Med 2004, I 1 8:267-273.

Publish with Bio Med Central and every scientist can read your work free of charge

"BioMed Central will be the most significant development for disseminating the results of biomedical research in our lifetime. "

Sir Paul Nurse, Cancer Research UK

Your research papers will be:

- available free of charge to the entire biomedical community

- peer reviewed and published immediately upon acceptance

- cited in PubMed and archived on PubMed Central

- yours - you keep the copyright
BioMedcentral 